\title{
Crystallization in diblock copolymer thin films at different degrees of supercooling
}

Darko, C.; Botiz, I.; Reiter, G.; Breiby, D.W.; Andreasen, Jens Wenzel; Roth, S.V.; Smilgies, D.-M.;

Metwalli, E.; Papadakis, C.M.

Published in:

Physical Review E

Link to article, DOI:

10.1103/PhysRevE.79.041802

Publication date:

2009

Document Version

Publisher's PDF, also known as Version of record

Link back to DTU Orbit

Citation (APA):

Darko, C., Botiz, I., Reiter, G., Breiby, D. W., Andreasen, J. W., Roth, S. V., Smilgies, D-M., Metwalli, E., \& Papadakis, C. M. (2009). Crystallization in diblock copolymer thin films at different degrees of supercooling. Physical Review E, 79(4), 041802. https://doi.org/10.1103/PhysRevE.79.041802

\section{General rights}

Copyright and moral rights for the publications made accessible in the public portal are retained by the authors and/or other copyright owners and it is a condition of accessing publications that users recognise and abide by the legal requirements associated with these rights.

- Users may download and print one copy of any publication from the public portal for the purpose of private study or research.

- You may not further distribute the material or use it for any profit-making activity or commercial gain

- You may freely distribute the URL identifying the publication in the public portal 


\title{
Crystallization in diblock copolymer thin films at different degrees of supercooling
}

\author{
C. Darko, ${ }^{1}$ I. Botiz, ${ }^{2}$ G. Reiter, ${ }^{2}$ D. W. Breiby, ${ }^{3}$ J. W. Andreasen, ${ }_{1}^{4}$ S. V. Roth, ${ }^{5}$ D.-M. Smilgies, ${ }^{6}$ E. Metwalli, ${ }^{1}$ and \\ C. M. Papadakis ${ }^{1}$ \\ ${ }^{1}$ Physikdepartment E13, Technische Universität München, James-Franck-Str. 1, 85747 Garching, Germany \\ ${ }^{2}$ Institut de Chimie de Surfaces et Interfaces, CNRS-UHA, 68057 Mulhouse, France \\ ${ }^{3}$ Department of Physics, Norwegian University of Science and Technology, Høgskoleringen 5, 7491 Trondheim, Norway \\ ${ }^{4}$ Ris $\phi$ National Laboratory for Sustainable Energy, Technical University of Denmark, Frederiksborgvej 399, DK-4000 Roskilde, Denmark \\ ${ }^{5}$ HASYLAB at DESY, Notkestr. 85, 22603 Hamburg, Germany \\ ${ }^{6}$ Cornell High Energy Synchrotron Source (CHESS), Wilson Laboratory, Cornell University, Ithaca, New York 14853, USA
}

(Received 15 July 2008; revised manuscript received 5 January 2009; published 21 April 2009)

\begin{abstract}
The crystalline structures in thin films of polystyrene- $b$-poly(ethylene oxide) (PS- $b$-PEO) diblock copolymers were studied in dependence on the degree of supercooling. Atomic force microscopy showed that the crystalline domains (lamellae) consist of grains, which are macroscopic at low and intermediate degrees of supercooling, but of submicrometer size for strong supercooling. Using grazing-incidence wide-angle $\mathrm{x}$-ray scattering, we could determine the grain orientation distribution function which shows that the chain stems are perpendicular to the lamellae at low supercooling, but tilted at intermediate and strong supercooling. These results suggest that, at intermediate and strong supercooling, the crystalline PEO lamellae do not grow homogeneously, but by the formation of small crystallites at the growth front.
\end{abstract}

DOI: 10.1103/PhysRevE.79.041802

PACS number(s): 82.35.Jk, 61.05.cf, 81.40.-z

Polymer crystallization, apart from its technological relevance, is a fascinating example of structure formation by molecular self-assembly featuring the interplay between different lengths and time scales [1-5]. Single chains orient parallel to each other forming quasi-two-dimensional lamellae, which may be macroscopically large, with the chains usually perpendicular to the surface of the lamellae [6-11]. Polymer crystallization involves both the diffusion of amorphous chains toward the growth front and their folding into regular structures. Complex processes at the growth front have been the subject of current discussion, such as the initial formation of small crystalline grains which eventually fuse to form a lamella $[1,12]$. The resulting granular substructure within crystalline polymer lamellae has been observed in direct-space observations by atomic force microscopy (AFM) and in wide-angle $\mathrm{x}$-ray scattering experiments $[12,13]$. Based on phase-field simulations, the loss of rotational freedom of the chains was proposed as a possible reason for the complex microstructures formed [1]. However, it is still not clear if an orientational correlation exists between chain stems of different grains.

Crystallization can be further controlled by nanoscale confinement $[4,8,9,14-16]$. In a diblock copolymer, two immiscible polymer chains are chemically bound which leads to the formation of self-organized nanostructures via microphase separation. Crystallization of one of the blocks may thus be confined by the microphase-separated block copolymer morphology, if the glass temperature of the amorphous block lies above the melting point of the crystalline block [8,14,17-20]. Otherwise, crystallization can break out and destroy the block copolymer domains by forming crystalline lamellae [21-23]. The molecular orientation within the crystalline domains formed has been characterized by scattering methods, and the domains were macroscopically oriented, e.g., by shear alignment $[8,17,24]$.

In thin-film geometry, lamellar structures align parallel to the substrate surface because of geometrical confinement as well as physico-chemical interactions at the substrate-film and the film-air interface $[7,11,16,25]$. Various microscopies as well as electron diffraction and x-ray reflectometry have been applied to thin films of block copolymers to correlate the surface domain topography to the mean thickness of the crystalline lamellae and the average chain orientation to the lamellar interface of the other block $[16,26]$. Additionally, block copolymer thin films offer the advantage that several crystalline lamellae (on the order of 10) separated by the amorphous block can be stacked without loss of lamellar orientation, thereby enhancing the scattering signal when compared to monolayers of crystalline polymers on a substrate $[3,27]$.

We present a study of structures resulting from crystallization of symmetric polystyrene- $b$-poly(ethylene oxide) (PS- $b$-PEO) diblock copolymers in thin-film geometry. Short chain lengths were chosen for both blocks (molar mass: 3000 $\mathrm{g} / \mathrm{mol}$ ) allowing to distinguish between different folding states of the PEO block. Moreover, from the Flory-Huggins segment-segment interaction parameter of the PS/PEO pair [28] together with the low block molar masses, a very low order-to-disorder transition (ODT) temperature is estimated for an amorphous block copolymer $\left(-90{ }^{\circ} \mathrm{C}\right)$, thus far below the crystallization temperatures used, i.e., the crystallization is unconfined $[29,30]$. This was confirmed by in situ grazingincidence small-angle $x$-ray scattering (GISAXS): the lamellar structure vanishes above $40{ }^{\circ} \mathrm{C}$, i.e., even below the melting point of PEO [31]. Thus, the microphase separation is primarily due to the crystalline structure of PEO and not to the repulsive interaction between PS and PEO.

The crystallization of the PEO blocks induces microphase separation from PS, which, in turn, leads to the creation of a layered film structure with crystalline PEO lamellae alternating with amorphous PS lamellae. We combined optical microscopy, AFM, and $\mathrm{x}$-ray scattering techniques to determine the orientation of the crystalline PEO blocks within the films. 
Strong, intermediate, and weak supercooling will be presented.

Thin polymer films were prepared by spin coating from toluene solution onto UV/ozone cleaned silicon wafers, resulting in film thicknesses of around $100 \mathrm{~nm}$. The wafer surface is preferential for PEO. After melting the PEO crystallites for $5 \mathrm{~min}$ at $62{ }^{\circ} \mathrm{C}$, i.e., just above the melting point $T_{m}=55^{\circ} \mathrm{C}$ of bulk PS- $b$-PEO, the films were quenched to the crystallization temperature $T_{x}$ of $25{ }^{\circ} \mathrm{C}$ or $50{ }^{\circ} \mathrm{C}$ (strong or weak supercooling, respectively) at a cooling rate of 50 $\mathrm{K} / \mathrm{min}$. The films were then kept at $T_{x}$ and the morphological changes in the surface during crystallization were followed with optical microscopy until the entire film $\left(1 \mathrm{~cm}^{2}\right)$ was crystallized and no further changes were observed. The sample preparation was carried out in a nitrogen atmosphere. Note that $T_{g}$ of the PS block is estimated to be at room temperature $[8,18,33]$, in contrast to earlier studies $[8,18,32]$ using higher molar mass polymers, where $T_{g}$ was above $T_{m}$, i.e., in the hard confinement regime.

The mesoscopic structure inside the film was investigated using GISAXS. Experiments were carried out at beamlines BW4, HASYLAB [34] and D1, CHESS [35] with sampleto-detector distances of 1.11 and $1.21 \mathrm{~m}$ and wavelengths of $\lambda=0.138$ and $0.124 \mathrm{~nm}$. The incident angle $\alpha_{i}$ was varied between $0.15^{\circ}$ and $0.50^{\circ}$, thus above the critical angle of the polymer film $\left(\alpha_{\mathrm{cp}}=0.14^{\circ}\right.$ for $\left.\lambda=0.138 \mathrm{~nm}\right)$. At these incident angles, the entire film contributes equally to the signal. Measurements were carried out at room temperature. The GISAXS maps are given as a function of $q_{x y}$ and $q_{z}$, the lateral and the normal components of the scattering vector, respectively. Repeat distances of the layers were calculated from the $q_{z}$ positions of the diffuse Bragg sheets within the framework of the distorted-wave Born approximation [36].

To determine the crystalline structure and orientation of the PEO block, we used grazing-incidence wide-angle $\mathrm{x}$-ray scattering (GIWAXS). Experiments were carried out using a Rigaku rotating anode $\mathrm{x}$-ray source with $\lambda=0.1542 \mathrm{~nm}$ in combination with a Fuji film image plate detection system [37] at a distance of $0.124 \mathrm{~m}$ from the sample. The incident angle $\alpha_{i}$ was fixed at $0.18^{\circ}$. Measurements were performed at room temperature. GIWAXS images were modeled with the SimDiffraction software $[38,39]$ using the bulk PEO lattice [40] and assuming that the films were laterally isotropic. Additional high-resolution diffraction experiments were carried out at beamline BW2 at HASYLAB.

Time-resolved optical microscopy (insets of Fig. 1) revealed that, at $T_{x}=25^{\circ} \mathrm{C}$ and at $40^{\circ} \mathrm{C}$, the density of nuclei was about 500 nuclei $/ \mathrm{mm}^{2}$ and the speed of the crystallization front was high $(5400 \mathrm{~nm} / \mathrm{s})$, whereas at $50{ }^{\circ} \mathrm{C}$, less than 1 nucleus $/ \mathrm{mm}^{2}$ was present, growing at a low rate of 2 $\mathrm{nm} / \mathrm{s}$.

AFM provided information on surface texture. At $T_{x}$ $=50{ }^{\circ} \mathrm{C}$ [Fig. 1(a)], the surface exhibited staggered and smooth terraces having an average height of $11.0 \pm 0.5 \mathrm{~nm}$. In contrast, at $T_{x}=25^{\circ} \mathrm{C}$ and at $40^{\circ} \mathrm{C}$ [Figs. 1(b) and 1(c)], a rough surface consisting of elongated small objects of about $100 \mathrm{~nm}$ in size was observed. We assign them to individual crystalline PEO grains which formed at the advancing growth front.

Two-dimensional (2D) GISAXS images of the crystal-

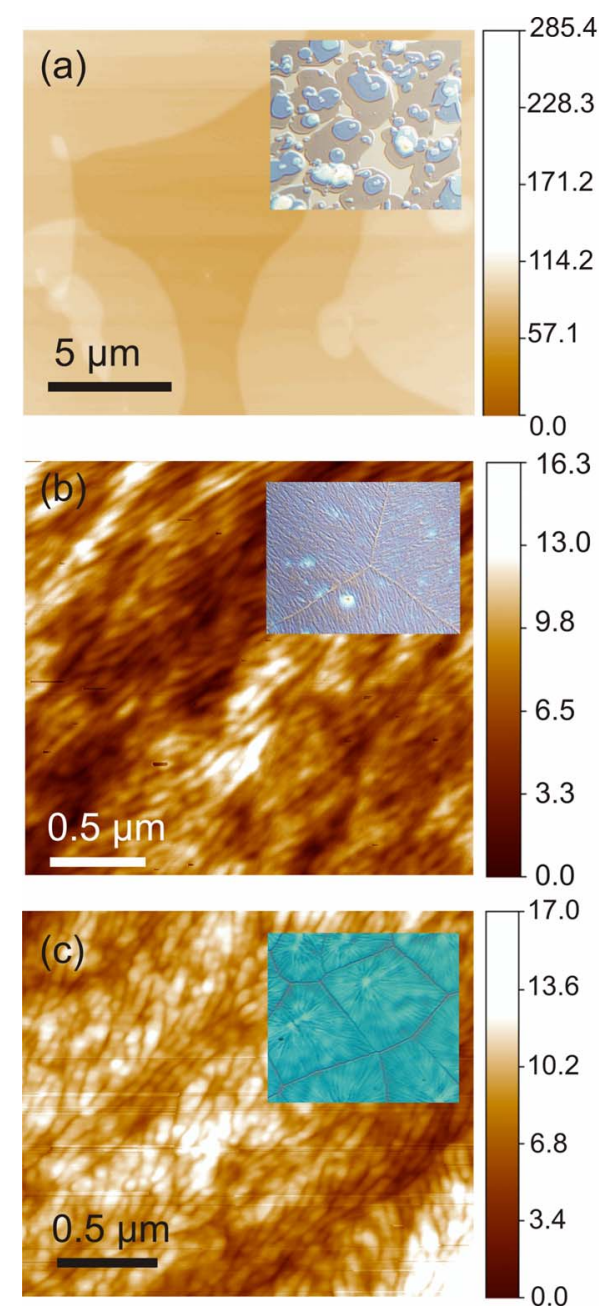

FIG. 1. (Color online) AFM topography images of films crystallized at (a) $T_{x}=50{ }^{\circ} \mathrm{C}$, (b) $40{ }^{\circ} \mathrm{C}$, and (c) $25^{\circ} \mathrm{C}$, all measured at room temperature. The height scales are given in $\mathrm{nm}$. The insets show optical micrographs with a size of $100 \times 100 \mu \mathrm{m}^{2}$.

lized films show weak intensity maxima along the $q_{z}$ axis (Fig. 2). We attribute these to diffuse Bragg sheets from crystalline PEO lamellae in the films having their interfaces parallel to the substrate, separated by amorphous PS layers. Fitting the $q_{z}$ positions of the diffuse Bragg sheets measured at several incident angles, the repeat distances were determined to be $16.0 \pm 0.5,20.0 \pm 0.7$, and $21.0 \pm 0.5 \mathrm{~nm}$ at $25^{\circ} \mathrm{C}$, $40{ }^{\circ} \mathrm{C}$, and $50{ }^{\circ} \mathrm{C}$, respectively [36]. The latter value is consistent with the one calculated for a bilayer of a once-folded PEO block with polymer chains oriented perpendicular to the lamellar surface and the attached coiled PS block of $23 \mathrm{~nm}$ [41]. The surface terraces of this film, as seen by AFM, consist either of a half lamella or of bilayers of twice-folded PEO.

The perpendicular orientation of the PEO chain stems at $T_{x}=50{ }^{\circ} \mathrm{C}$ is confirmed by GIWAXS [Fig. 3(a)]. The Bragg reflections from the PEO stems were indexed by simulating the 2D diffraction image of the PEO lattice [Fig. 3(b)]. The orientation of the crystallites was assumed to be rotationally isotropic around the film normal. We note, however, that at $T_{x}=50{ }^{\circ} \mathrm{C}$, this assumption is not ideally fulfilled: due to the 


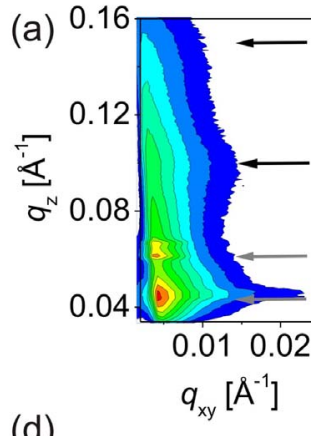

(d)
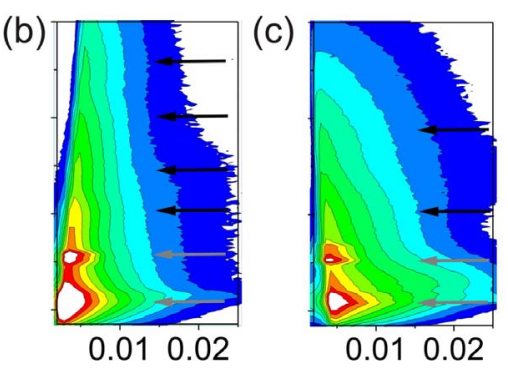

(e)
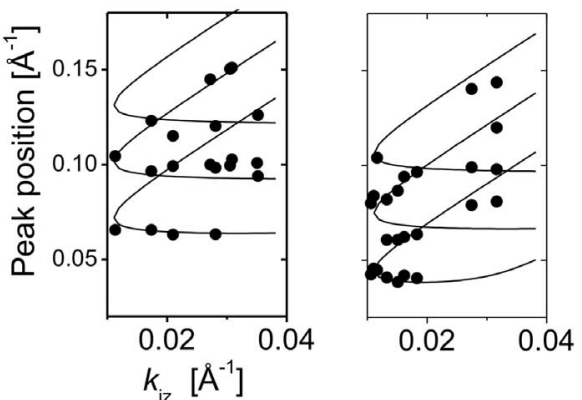

(f)

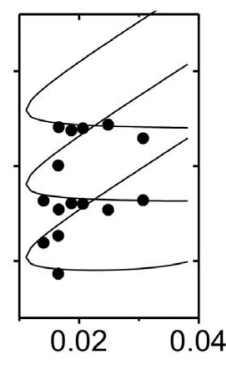

FIG. 2. (Color online) 2D GISAXS images of thin films crystallized at (a) $T_{x}=50{ }^{\circ} \mathrm{C}$, (b) $T_{x}=40{ }^{\circ} \mathrm{C}$, and (c) $T_{x}=25{ }^{\circ} \mathrm{C} . \alpha_{i}$ $=0.39^{\circ}$. The logarithmic intensity scale runs from 30 to 6000 . The arrows indicate (from bottom to top) the position of the Yoneda peak and the specularly reflected beam as well as the diffuse Bragg sheets. (d)-(f) Peak positions of the diffuse Bragg sheets as a function of incident wave vector, $k_{\mathrm{iz}}=2 \pi /\left[\lambda \times \sin \left(\alpha_{i}\right)\right]$, at the respective temperatures. Symbols: experimental values of the diffuse Bragg sheets (circles). Lines: model curves (see text).

large average size of the crystallite, the GIWAXS image exhibits some intensity variations of equivalent diffraction peaks on either side of the (vertical) symmetry line. Comparison of the experimental and simulated images shows that the $c$ axis of the unit cell (and thus the PEO chain stems) is perpendicular to the crystallite surface (i.e. the tilt angle with respect to the film normal is $\theta=0^{\circ}$ ) with a half-width at half maximum (HWHM) of the distribution of tilt angles of only $3^{\circ}$.

These findings are consistent with observations in the bulk [8]. The low growth rate seems to enable nearly perfect crystal growth within the film plane yielding a rather smooth surface topography, probably favored by a relatively high mobility of the PS blocks at this elevated temperature, facilitating lateral diffusion of the copolymers toward the growth front [Fig. 4(a)].

In contrast, the positions of the Bragg reflections in the image at $T_{x}=25^{\circ} \mathrm{C}$ indicate an average tilt angle of $35^{\circ}$ within large domains of about $50 \mu \mathrm{m}$ in diameter [Figs. 3(c) and 3(d)]. The azimuthal width of these reflections suggests that this tilt angle has a wide distribution. Using a Lorentzian with a HWHM of $13^{\circ}$, a reasonable agreement could be obtained. The chain stems thus seem to be inclined with respect to the lamellar interfaces, and their distribution of orientations is relatively wide. Assuming that all chains are once folded and tilted by $35^{\circ}$, this result implies an average repeat distance of $L=21.0 \mathrm{~nm} \times \cos \left(35^{\circ}\right)=17.2 \mathrm{~nm}$, which is in
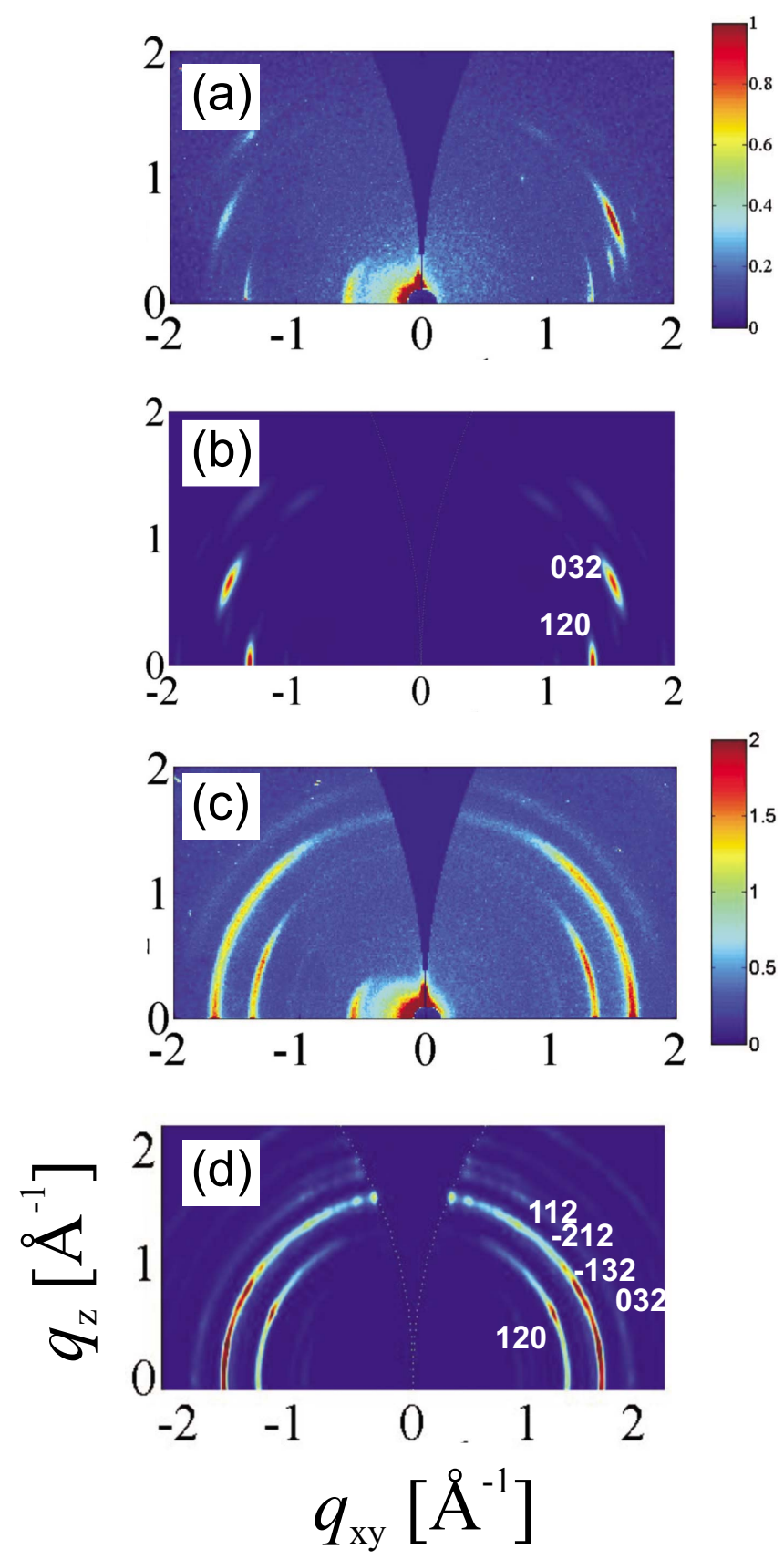

FIG. 3. (Color online) Experimental 2D GIWAXS maps of thin films crystallized at (a) $T_{x}=50{ }^{\circ} \mathrm{C}$ and (c) $25^{\circ} \mathrm{C}$, interpolated to reciprocal coordinates. The strong intensities close to the origin are due to parasitic scattering. (b,d) Corresponding simulated $2 \mathrm{D}$ patterns of the diffraction from PEO crystals for (b) $T_{x}=50^{\circ} \mathrm{C}$ and $\theta$ $=0^{\circ}$ with a HWHM of $3^{\circ}$, and (d) $T_{x}=25^{\circ} \mathrm{C}$ and $\theta=35^{\circ}$ with a HWHM of $13^{\circ}$.

good agreement with the repeat distance of $16.0 \pm 0.5 \mathrm{~nm}$ deduced from the GISAXS results. The average lateral size of the crystallite grains with uniform chain orientation is only about $50 \mathrm{~nm}$, as deduced from the width of the (120) reflection peak in the high-resolution grazing-incidence diffraction data (not shown), thus fully consistent with the grain size at the surface observed by AFM [Fig. 1(c)]. From the lamellar thickness at $40{ }^{\circ} \mathrm{C}$, we conclude accordingly an average tilt angle of $17^{\circ}$. 


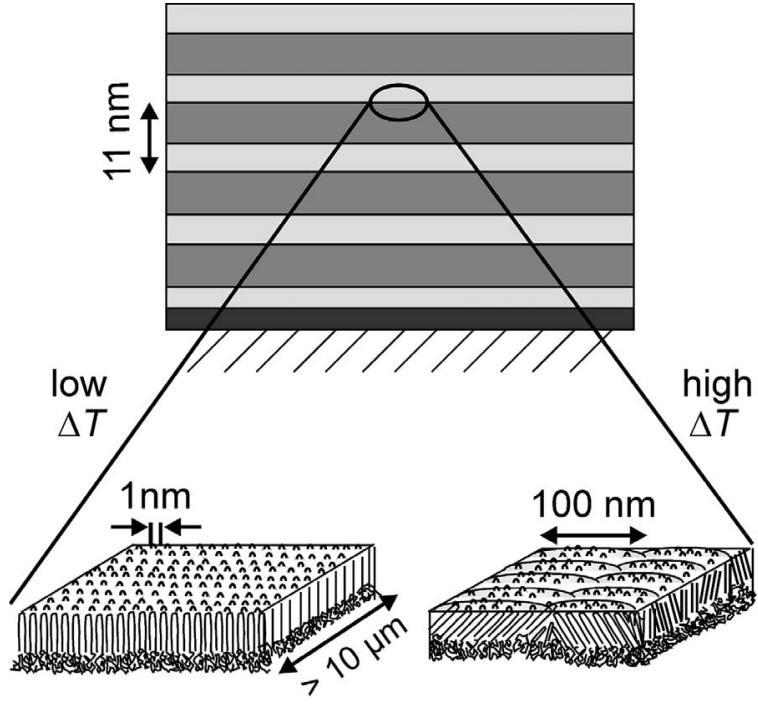

FIG. 4. Schematics of the structures of the film crystallized at (a) $50{ }^{\circ} \mathrm{C}$ and (b) $25^{\circ} \mathrm{C}$. Approximate length scales are indicated.

We conclude that each of the grains observed in the AFM image consists of chains with a specific inclination angle [Fig. 4(b)]. The tilt angle differs from grain to grain and seems to be uncorrelated between neighboring grains. We suggest that the crystalline domains, which grow at a constant growth rate from a single nucleation point, are not built up from a large lamella with uniformly oriented crystalline chains. A possible reason for such loss of unique orientation is repeated nucleation events at the growth front, as demonstrated recently in phase-field simulations [1]. The translational and rotational diffusions of PEO blocks may be additionally hindered by the more viscous PS layers at this low temperature, in contrast to the previously studied PB- $b$-PEO system where the perpendicular orientation prevailed $[16,26]$.

Interestingly, the size of these crystallites is in the same range as determined by Strobl and co-workers [13] for various chemically different polymers at similar degrees of supercooling. This small size of the crystallites was taken as strong evidence for a general route of polymer crystallization leading to a granular substructure of crystalline polymer lamellae. Thus, the experimental results presented here on polymer crystallization provide clear support for the hypothesis that large quasi-two-dimensional crystalline polymer domains (i.e., crystalline lamellae characterized by a welldefined repeat distance) are actually composed of small subunits. The lateral size of these subunits increases with decreasing supercooling: the grain size is already beyond the resolution limit of the GIWAXS instrument for the sample crystallized at $T_{x}=50{ }^{\circ} \mathrm{C}$. Our findings are also in qualitative agreement with the observations on shear-aligned PS- $b$-PEO in bulk [8], in spite of the differences in sample molar mass, preparation, and alignment. In addition to measuring the mean inclination angle, we have also simulated the width of the variation around this angle and have determined the lateral extension of crystalline grains, which was found to be consistent with the characteristic size of surface features observed by AFM. The thickness of the films which amounts to a few bilayers is sufficiently high such that substrate/polymer interactions during the crystallization can be neglected for the main part of the film. Future systematic experiments slowly varying the degree of supercooling will be devoted to studying the scaling of the domain size and correlate this with the average lamellar period and the average molecular tilt of the PEO stems.

Our work shows that only a detailed multiscale structural analysis can explain the observed surface morphologies and relate them to different mechanisms of crystal growth. The thin-film geometry used here offers an ideal possibility to correlate detailed structural analyses on various length scales with the direct-space observation of crystal growth via microscopy techniques, in order to deepen our understanding of polymer crystallization.

We thank K. Diller and S. Aschauer for the help with the experiments and J.-U. Sommer, B. Stühn, and M. Al-Hussein for stimulating discussions. Financial support by DFG (Contract No. Pa771/3) is gratefully acknowledged. CHESS is supported by NSF/NIH/NIGMS under Grant No. DMR0225180.
[1] L. Gránásy, T. Pusztai, T. Börzsöny, J. A. Warren, and J. F. Douglas, Nature Mater. 3, 645 (2004).

[2] P. Welch and M. Muthukumar, Phys. Rev. Lett. 87, 218302 (2001).

[3] G. Reiter, G. Castelein, and J.-U. Sommer, Phys. Rev. Lett. 86, 5918 (2001).

[4] M. Steinhart, P. Göring, H. Dernaika, M. Prabhukaran, U. Gösele, E. Hempel, and T. Thurn-Albrecht, Phys. Rev. Lett. 97, 027801 (2006).

[5] S. Kimata, T. Sakurai, Y. Nozue, T. Kasahara, N. Yamaguchi, T. Karino, M. Shibayama, and J. Kornfield, Science 316, 1014 (2007).

[6] A. Kovacs, C. Straupe, and A. Gonthier, J. Polym. Sci., Polym. Symp. 59, 31 (1977)
[7] G. Reiter, G. Castelein, P. Hoerner, G. Riess, J.-U. Sommer, and G. Floudas, Eur. Phys. J. E 2, 319 (2000).

[8] L. Zhu, S. Z. D. Cheng, B. Calhoun, Q. Ge, R. P. Quirk, E. L. Thomas, B. S. Hsiao, F. Yeh, and B. Lotz, J. Am. Chem. Soc. 122, 5957 (2000).

[9] S. Z. D. Cheng and B. Lotz, Polymer 46, 8662 (2005).

[10] R. M. Ho, T. M. Chung, J.-C. Tsai, J. C. Kuo, B. S. Hsiao, and I. Sics, Macromol. Rapid Commun. 26, 107 (2005).

[11] G.-D. Liang, J.-T. Xu, Z.-Q. Fan, S.-M. Mai, and A. J. Ryan, Macromolecules 39, 5471 (2006).

[12] T. Hugel, G. Strobl, and R. Thomann, Acta Polym. 50, 214 (1999).

[13] T. Hippler, S. Jiang, and G. Strobl, Macromolecules 38, 9396 (2005). 
[14] Y.-L. Loo, R. A. Register, and A. J. Ryan, Phys. Rev. Lett. 84, 4120 (2000).

[15] G. Reiter, G. Castelein, J.-U. Sommer, A. Röttele, and T. Thurn-Albrecht, Phys. Rev. Lett. 87, 226101 (2001).

[16] R. Opitz, D. M. Lambreva, and W. H. de Jeu, Macromolecules 35, 6930 (2002).

[17] I. W. Hamley, J. P. A. Fairclough, N. J. Terrill, A. J. Ryan, P. M. Lipic, F. S. Bates, and E. Towns-Andrews, Macromolecules 29, 8835 (1996).

[18] L. Zhu et al., Macromolecules 35, 3553 (2002).

[19] A. Röttele, T. Thurn-Albrecht, J.-U. Sommer, and G. Reiter, Macromolecules 36, 1257 (2003).

[20] L. Li, Y. Séréro, M. H. J. Koch, and W. H. de Jeu, Macromolecules 36, 529 (2003).

[21] A. J. Ryan, I. W. Hamley, W. Bras, and F. S. Bates, Macromolecules 28, 3860 (1995).

[22] D. J. Quiram, R. A. Register, and G. R. Marchand, Macromolecules 30, 4551 (1997).

[23] Y. L. Loo, R. A. Register, and A. J. Ryan, Macromolecules 35, 2365 (2002).

[24] P. Huang, L. Zhu, S. Z. D. Cheng, Q. Ge, R. P. Quirk, E. L. Thomas, B. Lotz, B. S. Hsiao, L. Liu, and F. Yeh, Macromolecules 34, 6649 (2001).

[25] I. Potemkin, P. Busch, D.-M. Smilgies, D. Posselt, and C. Papadakis, Macromol. Rapid Commun. 28, 579 (2007).

[26] S. Hong, L. Yang, W. J. Macknight, and S. P. Gido, Macromolecules 34, 7009 (2001).

[27] G. Reiter and J.-U. Sommer, Phys. Rev. Lett. 80, 3771 (1998).

[28] H. Frielinghaus, N. Hermsdorf, K. Almdal, K. Mortensen, L. Messé, L. Corvazier, J. Fairclough, A. Ryan, P. Olmsted, and I. Hamley, Europhys. Lett. 53, 680 (2001).

[29] S. Nojima, K. Kato, S. Yamamoto, and T. Ashida, Macromolecules 25, 2237 (1992).
[30] P. Rangarajan, R. A. Register, and L. J. Fetters, Macromolecules 26, 4640 (1993).

[31] C. Papadakis, C. Darko, D. M. Smilgies, S. Förster, K. Troll, Z. Di, and A Timmann (unpublished).

[32] Polymer Handbook, 2nd ed., edited by J. Brandrup and E. H. Immergut (Wiley, New York, 1975), Chap. 4, p. 337.

[33] J. Zheng, H. Xiong, W. Chen, K. Lee, R. V. Horn, R. Quirk, B. Lotz, E. Thomas, A.-C. Shi, and S. Cheng, Macromolecules 39, 641 (2006).

[34] S. V. Roth, R. Döhrmann, M. Dommach, M. Kuhlmann, I. Kröger, R. Gehrke, H. Walter, C. Schroer, B. Lengeler, and P. Müller-Buschbaum, Rev. Sci. Instrum. 77, 085106 (2006).

[35] D.-M. Smilgies, P. Busch, C. M. Papadakis, and D. Posselt, Synchrotron Radiat. News 15, 35 (2002).

[36] P. Busch, M. Rauscher, D.-M. Smilgies, D. Posselt, and C. M. Papadakis, J. Appl. Crystallogr. 39, 433 (2006).

[37] D. Apitz, R. P. Bertram, N. Benter, W. Hieringer, J. W. Andreasen, M. M. Nielsen, P. M. Johansen, and K. Buse, Phys. Rev. E 72, 036610 (2005).

[38] D. W. Breiby and E. J. Samuelsen, J. Polym. Sci., Part B: Polym. Phys. 41, 2375 (2003).

[39] D. W. Breiby, O. Bunk, J. W. Andreasen, H. T. Lemke, and M. M. Nielsen, J. Appl. Crystallogr. 41, 262 (2008).

[40] Y. Takahashi and H. Tadokoro, Macromolecules 6, 672 (1973).

[41] The chain length $L=0.5 l_{u} N_{\mathrm{PEO}}$ of a once-folded PEO of molar mass $3000 \mathrm{~g} / \mathrm{mol}$ is $9.5 \mathrm{~nm}$, where $l_{u}=0.2783 \mathrm{~nm}$ [40] is the PEO monomer length and $N=68$ is the degree of polymerization of the PEO block. The thickness of the amorphous PS layer is estimated by dividing the volume of the PS block by the cross-sectional area of two stems formed by a PEO block in the crystalline state [40], which results in $L_{\mathrm{PS}}=2.0 \mathrm{~nm}$. The thickness of a bilayer corresponding to the lamellar period is thus roughly $L=2\left(L_{\mathrm{PEO}}+L_{\mathrm{PS}}\right)=23.0 \mathrm{~nm}$. 